\title{
Lexico-Semantic Features of Phraseological Units Denoting Parts of The Human Body
}

\author{
Gulnoza Teshaboeva \\ Senior Lecturer, Department of Primary Education \\ Faculty of Education, Andijan State University
}

\begin{abstract}
The article examines the lexical and semantic nature of the phraseological unit associated with the names of parts of the human body. This work describes the meaning of phraseological units expressed in a literary text, and the expressive meanings of the text in external speech.
\end{abstract}

Key words: literary text, phraseological unit, person, writer, lexical and semantic features.

Reading a literary text, we come across a lot of phraseological units that are expressed as figurative means. In particular, such aggregates are associated with the names of parts of the human body. For example: "pour into the ear", "close your eyes", "like a chicken with burnt legs", "take over", "reach the head" and so on. Such units, as noted above, facilitate the emotional transmission of an idea to the listener. Phraseological units associated with the names of parts of the human body are widely used in a literary text to describe a character, state, psyche and similar images. That is, if we look at their lexical semantics, one phraseological unit expresses a different meaning in context. For example: "The face of his wife opened up, and when she turned, she said with a girlish smile: ........." (A. Kakhhor. "The woman who did not eat raisins")

The phrase "open face" used in this sentence served the art of speech. It is noted that this phrase in the "Explanatory Phraseological Dictionary of the Uzbek Language" by Sh. Rakhmatullaev means to be happy, to dispel sadness, to be in a good mood. The same can be understood in the example. This phraseological unit of speech is expressed in the name of a part of the human body. The word face is a textual synonym with a positive connotation. At the same time, it is an emotionally expressive vocabulary. The use of expressive vocabulary depends on the general purpose and direction of the text. The word face is a textual synonym, which, in turn, forms a synonymous line with words such as sur, front, look, confront, confidence, cover. And they differ from each other in that they have a positive and negative connotation.

The writer finds the most suitable meaningful words for the purpose of the image and tries to express the psyche of the main characters and the smallest details of the object of the image. In linguistics, there are three types of synonyms:

1) lexical meanings;

2) phraseological meanings;

3) lexico-phraseological meanings.

The above example shows a phraseological meaning. That is, a compound word can be freely replaced with such phraseological units as "the face smiles", "the face is shining", "the face is revealed". And here the human body is also considered an important unit of the name. The expression "face opened" also has lexical and phraseological meaning. However, if we take this 
phrase as a lexico-phraseological combination and replace it with the phrase be happy, as mentioned above, the semantic expression will be very narrow. Therefore, one should consider open face as a phraseological link. Because even if we replace one of the synonyms with the above, it is natural that there will be enough expressiveness.

The meaning of phraseological units is widely used in the figurative description of reality, in its clear and complete embodiment in the eyes of the reader. In the above example, if we replace the phrase "His wife was delighted and turned away, leaving ............", we will be able to understand the state of happiness of the protagonist as a whole, formally, more precisely, relatively abstractly. In another case, we feel not only the mood of the character, but also his psyche. The image of her face comes to mind, and it is easy to see that female happiness came instantly.

It is usually not enough for a writer to use phrases that fit the purpose of the image. Perhaps, the character, mood and lifestyle of the main characters are changing and reworking. This idea should not contradict the fact that phraseological units are ready for introduction into speech, that is, phrases are ready for introduction into speech, but the writer can rework them for a specific purpose. For example:

"After that, if we allow such arbitrary actions of the villagers, we will soon have to wash our hands of the village." (Cholpon. Day and night). The abbreviation of this phrase in the form of washing one's hands in the speech of Noyib Tura served not only for the brevity of the form, but also for changing the meaning. Under the use of the phrase of Noyib Tury, Marufjon Yuldashev noted that the phrase "if the situation continues, we will have to leave the village in the near future". It can be seen that an abbreviated version of the same phrase has enriched textual art with new semantic aspects, such as "leave", "separate", "escape".

The names of parts of the human body are often associated with eyes. For example: "imagine before the eyes", "darkened in the eyes", "close the eyes", "not seen or heard", "twitching eyes", "sharp eyes" and so on. This line can be continued further. Using such expressions in a literary text, a writer can figuratively describe various situations.

For example, "Thousands of pedestrians and horsemen appeared in the blink of an eye". (A. Kahhor. "Prophecy")

In this example, the phrase blinking an eye is used to describe an event that happened or will happen semantically quickly. The phrase is interpreted in the Uzbek explanatory phraseology as "in a very short time, quickly". Its synonyms are the phrases "hash-pash" and "ha-hu". These phrases were invented by people and taken from practice. Because in fact, in the blink of an eye, it is a very short time.

If we look at the semantics of a phrase in context, the dictionary gives an example: "Winter. This is one of those darkening of the eyebrows when he burst into the blink of an eye».

In this example, the phrase also refers to a very short and fleeting time. In addition, this example contains another phrase associated with the names of human organs: "darkening of the eyebrows". There are two different lexical expressions in this phrase. On the one hand, the phrase "darkening of the eyebrows" is a little closer to the phrase "in the blink of an eye", and on the other hand, the phrase "darkening of the eyebrows" is a metaphor. That is, the blackness of the eyebrows is like the blackness of the evening. The sentence had lexical and phraseological meaning. Using two phrases side by side makes speech more expressive and concise.

Or:

- "Eyes fell on a dilapidated mosque across the street" (A. Kakhhor. "People with Tails"). 
In the following example, the phrase associated with the eye also served as an emotional stimulus. The lexical semaphore of the phrase "eyes fell" is interpreted in annotated phraseological dictionaries as the sudden appearance of someone or something. A synonym for this phrase is the phrase "catch the eye".

As you know, most phraseological units are used in a figurative sense. If we replace them with our own designations, artistic discourse becomes a simple dry utterance with a slight deviation from the expressive one. Let's compare:

- $\quad$ "Eyes fell on a dilapidated mosque across the street".

- $\quad$ "I saw a dilapidated mosque across the street".

Both sentences are semantically, as a rule, equal. However, the expressive power of the denotative form of the phrase used in the second sentence is lower than in the first sentence. In the first example, the phrase refers to an event that happened unexpectedly. We can also see from the above context that the phrase differs from the conjunction used in the original meaning of the next sentence in the subtlety of meaning. If the first sentence expresses an unintended, unexpected event, the second sentence can express an unexpected action, as well as the expected expression of a connection in another speech situation.

Phraseological units have the same valence as other linguistic units in speech. And, in turn, they enter into syntagmatic relationships. The syntagmatic connection of lexemes associated with phraseology is important. At the same time, the phraseological siege is closely related to their valence. Semantic valence provides a syntagmatic relationship between a lexeme and a phrase, as well as between phraseologies. The emergence of the ability of phraseological units to communicate with other linguistic units is manifested through syntagmatic relations. ${ }^{1}$ Phraseological units can be included in different syntactic situations of speech. This connection complements and clarifies the meaning of phraseological units. For example, in the above example:

\section{"Thousands of pedestrians and horsemen appeared in the blink of an eye".}

The phrase in the blink of an eye in the example contains semantics such as instantly, quickly. The valence of the phrase in the blink of an eye in the sentence is clearly expressed in the syntagmatic relation of the essence of the phrase to the word appearing.

\section{REFERENCES}

1. Sh. Rakhmatullaev. "Annotated phraseological dictionary of the Uzbek language"8

2. M. Yuldoshev. "Linguistic analysis of literary text"

3. Nurmonov A. "Modern Uzbek literary language"

4. Journal of the Uzbek language and literature / 2016

5. Abdurakhmanov Sh. "Linguistic Means of Laughter in Uzbek Artistic Speech".

6. A. Kakhhor. "Pomegranate" collection of short stories.

\footnotetext{
${ }^{1}$ Ganieva. Sh. "On the state significance of phraseology" / Uzbek language and literature. No. 1, 2016, p. 103 /
} 